'Proving non-fatal strangulation in domestic violence cases'. Authors: Heather Douglas and Robin Fitzgerald. Accepted version: International Journal of Evidence \& Proof.

\title{
Proving non-fatal strangulation in domestic violence cases: A case study on the criminalisation of domestic violence.
}

\author{
Heather Douglas and Robin Fitzgerald \\ Author contact: douglash@unimelb.edu.au
}

\section{Introduction}

Non-fatal strangulation (NFS) is now recognised as extremely dangerous because of the serious, but often invisible, injuries it can cause, and the high risk of future harm and death associated with it, especially when carried out in the context of domestic violence (Turkel, 2007; Funk \& Schuppel, 2003). Researchers and practitioners have identified shortcomings in the criminal law response to NFS and argued for the introduction of a specific criminal offence to deal with this form of domestic violence (Special Taskforce on Domestic Violence in Queensland, 2015). One study has suggested that in those places where there is not a non-fatal strangulation offence available, the charge of assault is the most common charge - if there is any charge at all (Gombru, Brignell \& Donnelly, 2016). Assault does not identify the behaviour at the heart of the charge and assaults often result in low level penalties that do not reflect the seriousness of the behaviour. While more serious forms of assault or offences causing injury may be available to be charged in response to some incidents of non-fatal strangulation, the behaviour often leaves no visible injury, despite its seriousness. In some cases, attempted murder may be an option, but it may be difficult to prove intent to cause serious harm or death (Fitzgerald \& Douglas, 2014). In response to research highlighting the serious harms and risks associated with NFS and to the perceived undercharging of it, many American states established discrete offences of non-fatal strangulation throughout the 2000s (Pritchard, Reckdenwald \& Nordham, 2017). Most Australian jurisdictions, Canada and New Zealand have subsequently followed their lead, introducing, discrete offences of NFS (Edwards \& Douglas, 2021). ${ }^{1}$ England and Wales have also introduced a non-fatal strangulation offence in 2021 (Domestic Abuse Act 2021 (England and Wales) s75A).

In 2015, the Special Taskforce on Domestic and Family Violence in Queensland recommended that a 'dedicated offence for this serious and violent act needs to be added to the Code and an appropriate penalty applied that takes into account that the act of strangulation within a domestic violence situation is a predicator of escalation and increased risk to the victim' $(2015$, p.21). In response, the AttorneyGeneral introduced the Criminal Law (Domestic Violence) Amendment Bill (No. 2) 2015 (the Bill) which proposed an NFS offence. A parliamentary inquiry fielded submissions on the Bill, and these were generally supportive of the introduction of the offence, with the exception of the Queensland Bar Association (Legal Affairs and Community Safety Committee, 2016). It disagreed with the introduction of the offence, contending that the way the offence was drafted would invite argument 'potentially involving medical evidence and evidence from complainants' (Legal Affairs and Community Safety Committee, 2016, p. 13). They reasoned that prosecuting authorities may have difficulties satisfying the evidential

\footnotetext{
${ }^{1}$ In Australia see Crimes Act 1900 (ACT) ss28(2)(a); 27(1); Crimes Act 1900 (NSW) s37(1A); Criminal Code Act (NT) 1983 s186AA; Criminal Code Act 1899 (Qld) s315A; Criminal Law Consolidation Act 1935 (SA) s20A; Criminal Code Compilation Act 1913 s298. In Canada, see Criminal Code 1985, s267 and in New Zealand see Crimes Act 1961, s189A.
} 
threshold for the offence and that it may be common that medical evidence and complainant evidence is successfully challenged by the defence. The offence was subsequently introduced into law and has been charged regularly each year since its introduction. However, only around half of the NFS charges lodged at the magistrate's courts in Queensland result in a conviction and sentence (Queensland Courts, 2021a). As the Bar Association predicted, the lower conviction rate may reflect the challenging evidential threshold for the specific offence. Alternatively, it may be the case, as Howe (2012, p.149) has argued, that women's harms are often 'dismissed in legal culture' and that engaging with criminal law may create distress and disillusionment (Gruber, 2020; Mills, 1998; Coker, 2001). An investigation of this new offence offers an opportunity to investigate not just the NFS offence but also to reconsider the role of the criminal law in responding to domestic violence more generally.

In this study, we asked 17 lawyers who are involved in the prosecution and defence of NFS in Queensland, about the kinds of evidence that were important in securing a successful prosecution of NFS and specifically about the role of medical evidence and the evidence of complainants in the prosecution of NFS. Ultimately, we found that despite NFS being a physically violent and single incident crime the complainant's testimony and her willingness to testify are pivotal in most successful prosecutions of NFS. While medical evidence was generally perceived to be ambivalent about the relationship between perceptible injuries and NFS, medical evidence was useful when used to explain to juries that lack of injury is not inconsistent with NFS.

This article outlines evidence on the dangers and risks associated with NFS before reviewing research about evidential issues associated with prosecuting domestic violence crimes in general and the offence of NFS in particular. We then turn to explore the context in which our qualitative study was undertaken and the results of our study before ending with a discussion of our findings and conclusions.

\section{The risks and harms of non-fatal strangulation}

International research has identified that NFS is commonly experienced as a form of 'coercive control', or part of the pattern of controlling manipulative behaviours, within intimate partner relationships (Thomas, Joshi and Sorensen, 2014: 125). Research has also indicated that NFS is a relatively common form of abuse among women who experience intimate partner violence. Sorenson and colleagues' reviewed 23 articles based on 11 self-report surveys in nine countries and found that the percentage of women who reported having been strangled by an intimate partner ranged from three per cent to nearly ten per cent (Sorensen, Joshi and Sivitz, 2014, p. e57). In our previous study of 656 protection order applications submitted to a Queensland court over two years (2008-09 and 2009-10), we found that 12 per cent of women who applied for a protection order alleged an incident of NFS in their application (Douglas and Fitzgerald, 2014, p. 46). In a study involving interviews with women in shelters, researchers found that 68 percent had been strangled, usually by the intimate partner (Wilbur, Higley, Hatfield et al., 2001). In a recent qualitative study involving interviews with 65 Queensland women who had experienced intimate partner violence we found that 24 of the women (36 per cent) had experienced NFS during their intimate relationship (Douglas and Fitzgerald, 2020). In a study of women presenting at an emergency department in Brisbane, Australia in 2017, 26 per cent of them reported NFS (Marks et al., 2020: 676). Evidence also shows that in Australia around 14 per cent of family homicide deaths of women are caused by strangulation and or suffocation (Australian Institute of Criminology, 2019, p. 33; Australian Institute of Criminology, 2020a, p.11; Australian Institute of Criminology, 2020b, p. 11; Bricknell, 2020, p. 11). 
'Proving non-fatal strangulation in domestic violence cases'. Authors: Heather Douglas and Robin Fitzgerald. Accepted version: International Journal of Evidence \& Proof.

NFS is associated with many forms of non-fatal injury and health complications including difficulty swallowing, breathing, bruising, petechial haemorrhages, pre-term birth and miscarriage (Foley, 2015; Funk and Schuppel, 2003) and voice changes (Wilbur, Higley, Hatfield et al., 2001). NFS can cause hypoxia, or oxygen deficiency, resulting in brain injury which may manifest in unconsciousness, headaches, PTSD, anxiety, depression and issues with memory and concentration (Foley, 2015; Funk \& Schuppel, 2003; Bichard, Byrne, Saville \& Coetzer, 2021). Injuries will vary depending on the location where force is applied, how much force is exerted, the duration of time that the blood vessels and airway are obstructed, and how the NFS is carried out (Zilkens, Phillips, Kelly, et al., 2016). NFS is also associated with the risk of future serious harm and death, with one study finding that victims of NFS perpetrated by their partner or former partner were over seven times more likely to be a victim of homicide or very serious harm in the future (Glass, Laughon, Campbell et al., 2008).

\section{Evidential issues in domestic violence crimes including NFS}

NFS often leaves no visible trace. In a review of 300 NFS cases, Strack, McClane and Hawley (2001) found that only 50 per cent of strangulation survivors had any visible injuries and only 15 per cent of those with visible injuries had an injury that was severe or clear enough to be photographed for evidential purposes. Subsequent studies have similarly identified that it is common for victims of NFS to have no visible injuries (Joshi, Thomas \& Sorenson, 2012; Matusz, Schaffer, Bachmeier et al., 2020; Pritchard, Reckdenwald \& Nordham, 2017). Where victims have darker skin, it may be more difficult to see injuries (Baker and Sommers, 2008). While NFS offences do not typically require evidence of an injury, police and prosecutors may be reluctant to pursue prosecution, and juries may be hesitant to convict where there is no visible injury (Reckenwald, King \& Pritchard, 2020, p. 161). In their study of non-fatal strangulation cases submitted for prosecution in an American state, Strack, McClane and Hawley (2001) found that 25 per cent of cases were rejected for prosecution because there was a lack of corroborating evidence beyond minimal visible injuries such as redness, cuts, bruising of the neck that were often too minor to photograph with the quality necessary for trial. Yet, Strack and Gwinn (2011, p. 33-34) contend that many victims do have internal injuries as result of NFS but a lack of medical training about NFS has led medical practitioners to minimise NFS (Strack \& Gwinn, 2011, p. 33-34). Such internal injuries are more difficult to investigate and, in some cases, may require health practitioners to use technologies to identify internal injuries or complex tests around neurological damage (Monahan, Purushotham \& Biegon, 2019). In a more recent study of the operation of the NFS charge in Florida, Reckenwald, King and Pritchard (2020, p. 168) found that for over 60 per cent of complaints made to police where NFS was reported there was no charge. In England and Wales, Edwards has observed that the lack of visible injury can be used by the defence to negate complaints of assault-NFS and the degree of force used, its seriousness and dangerousness (Edwards, 2015).

Strack and Gwinn argue that better information and training about NFS is the solution to the problem of poor prosecution outcomes. They claim that judges and juries have difficulty understanding the seriousness of NFS without hearing evidence from experts, and they have highlighted the importance of testimony of experts in successful prosecutions of NFS (Strack \& Gwinn, 2011: 69; see also Jordan et al., 2020: 194). In these cases, Strack and Gwinn argue that experts can serve the purpose of 'teaching jurors about medical, technical, or scientific principles or expressing an opinion after evaluating the significance of the facts of the case' (Strack \& Gwinn, 2011, p. 69).

While Strack and Gwinn's work demonstrates that expert testimony can be important when there is physical evidence to explain, they also highlight the failure of medical experts to investigate the possibility that there are internal injuries. Studies suggest that for many other reasons, evidence in connection to 
NFS may be lacking. Many victims do not seek healthcare immediately after experiencing NFS and, if they do, the healthcare provider may not know what to look for (Patch, Anderson \& Campbell, 2018, p. 391). In some situations where victims attend their health provider days after the event, medical assessment and subsequent testimony may rely significantly on the victim's narrative of events, a narrative that may be inconsistent and confused as a result of the physical and mental trauma associated with the experience of domestic violence and NFS (Faugno, Waszak, Strack, et al., 2013; Ellison \& Munro, 2017: 184). Moreover, like other forms of domestic violence and sexual assault, there is unlikely to be a third-party witness to the event (Epstein and Goodman, 2018; Hunter, 1996: 160), thus, in many cases of NFS the victim's testimony may be key to a successful prosecution. Many researchers have pointed to the 'systemic disbelief of women who are victims of ... domestic violence' and the discounting of their stories of events (Simon-Kerr, 2021:3). That disbelief is enhanced where victims delay reporting to police and other health providers or provide inconsistent accounts (Hunter, 1996, p. 157; Ellison \& Munro, 2017, p. 186).

Any inconsistency in testimony, regardless of the reasons for it, are likely to be exploited by defence lawyers to suggest the testimony is unreliable (Ellison, 2005, p. 241, 249). In their consideration of the evidential barriers to prosecuting the ongoing offence of coercive control in England and Wales, Bishop and Bettinson (2018: 4) point to the limitation of the criminal law in its primary focus on isolated instances of violence. In terms of proof, NFS can be understood as an isolated incident offence and perhaps should be easier to prove (Australian Law Reform Commission [ALRC], 2010, [13.6]; Youngs, 2015, p 61-62) compared to an offence underpinned by an on-going pattern of behaviours such as coercive control. However, the evidential barriers acknowledged may be consistent with the problems of prosecuting domestic violence related behaviours generally, for example the focus on the credibility of victims, than whether offences capture single instances, like NFS, or on-going patterns of behaviour like coercive control.

Victims of domestic violence also often do not report, delay reporting, or withdraw their complaints of harm for a variety of reasons including fear of their partner (Dowling et al., 2018: 19) but also, what Gruber (2020: 194) refers to as 'converging interests' such as an interest in maintaining family, economic security and housing and fears of the intervention of the state through police, child protection services and immigration authorities. Many researchers have drawn attention to the ambivalence of victims in testifying against their intimate or former intimate partners in criminal prosecutions of domestic violence related harm (Robinson \& Cook, 2006; ALRC, 2010, [18.4]). Research has indicated that a high proportion of victims withdraw their support for prosecution after making their initial complaint and that without victim participation many domestic violence prosecutions do not proceed (Ellison, 2002, p. 761). Bishop and Bettinson (2018, p. 6) argue there is a clear distinction between compelling someone to testify, ${ }^{2}$ which they argue is inappropriate, and the trial proceeding regardless of the victim's position and in the absence of her testimony, which they support. Proceeding in the absence of the victim's testimony relies on the availability of other forms of evidence but also assumes that the the state should have an interest in the prosecution of domestic violence related offences in the absence of the victim's support, a position that some researchers argue may be contested and unclear in many cases (Gruber, 2020, p. 194; Robinson, 2014; Goodmark, 2018).

\section{The study}

${ }^{2}$ cf USA and the no-drop prosecution approach where victims may be coerced to testify (Ford, 2003) 


\section{Study context}

In Queensland the offence of 'Choking, suffocation or strangulation in a domestic setting' was introduced into Queensland law in 2016. It is set out in the Queensland Criminal Code 1899 (QId) (QCC) at section 315A:

(1) A person commits a crime if-

(a) the person unlawfully chokes, suffocates or strangles another person, without the other person's consent; and

(b) either-

(i) the person is in a domestic relationship with the other person; or

(ii) the choking, suffocation or strangulation is associated domestic violence under the Domestic and Family Violence Protection Act 2012.

Penalty - Maximum penalty -7 years imprisonment.

(2) An assault is not an element of an offence against subsection (1). ${ }^{3}$

There is no definition of NFS included in the QCC but the Queensland Court of Appeal has stated that 'in order to amount to choking, there must be some pressure that results at least in the restriction of the victim's breathing' ( $R$ v HBZ [2020] QCA 73). ${ }^{4}$ In her consideration of the definition of NFS Mullins JA (with whom McMurdo JA and Boddeice agreed) stated:

The gravamen of the offending conduct which the offence seeks to deter is the action of one domestic partner towards the other that is described as either choking, strangling or suffocating the victim and not the consequence of the act. The rationale for the offence is that even though one incident in the domestic context of choking, strangling or suffocating may not result in any serious injury, the conduct must be deterred, because it is inherently dangerous and experience shows that if it is repeated, death or serious injury may eventually result. In order to achieve the purpose of the introduction of this offence, "chokes" must be construed as the act of the perpetrator that hinders or restricts the breathing of the victim and does not require proof that breathing was completely stopped, although the hindering or restriction of the breathing would encompass the stopping of the breathing. ( $R$ v HBZ [2020] QCA 73 [56]-[57])

\footnotetext{
${ }^{3}$ Queensland law includes a complete defence of provocation to an offence of which assault is an element (see Criminal Code 1899 (Qld) ss 268, 269. By virtue of Criminal Code 1899 (Qld) s315A(2) excluding assault as an element of the NFS charge the provocation defence is not available.

${ }^{4}$ This definition appears to be fairly settled; the High Court has refused special leave to appeal (HBZ $v R$ [2020] HCATrans 187). Note that Queensland is a 'Code state'. A similarly structured offence of NFS was introduced into South Australia (a common law state), see Criminal Law Consolidation Act 1935 (SA) section 20A. In Rv Fraser [2020] SADC 127, [32] Judge Fuller stated the elements of the offence are:

- At the time of the alleged offence the accused was or had been, in a relationship with the complainant.

- The accused intentionally engaged in conduct which choked, suffocated or strangled the complainant; that is conduct that stopped or significantly hindered or restricted the complainant's respiration. In the alternative, the accused engaged in the conduct which choked, suffocated or strangled the complainant foreseeing that it was probable that this conduct would stop or significantly hinder or restrict the complainant's respiration.

- The complainant did not consent to being choked, suffocated or strangled.

- The act of choking, suffocating or strangling the complainant was done without lawful justification.
} 
In the three years since the introduction of the offence of NFS in the state, nearly $45 \%$ of charges of NFS have resulted in a conviction (see Table 1) (Queensland Courts, 2021a).

\begin{tabular}{|l|l|l|l|}
\hline Year & $\begin{array}{l}\text { Number of Offences } \\
\text { of non-fatal } \\
\text { strangulation (QCC } \\
\text { s315A) lodged at } \\
\text { magistrates' courts }\end{array}$ & $\begin{array}{l}\text { Number of defendants } \\
\text { convicted of NFS }\end{array}$ & $\begin{array}{l}\text { Percent of defendants } \\
\text { convicted of NFS }\end{array}$ \\
\hline $2017-2018$ & 834 & 353 & 42.3 \\
\hline $2018-2019$ & 676 & 332 & 49.1 \\
\hline $2019-2020$ & 592 & 258 & 43.6 \\
\hline Total & 2102 & 943 & 44.9 \\
\hline
\end{tabular}

Table 1: Queensland Courts' Domestic and Family Violence Statistics

In NFS cases, complainants routinely have access to 'special witness' protections (Evidence Act 1977 (Qld, s 21A; in England and Wales see: Burton, Evans \& Sanders, 2007 ) meaning they are allowed to give their evidence in a room other than the court room, via video recording or to give their evidence with extra rest breaks or in other circumstances that the court considers appropriate. Notably a charge of NFS must be heard in the District Court and if the charge is contested a jury will be empanelled. The period between initial charge until final hearing in the District Court can take 12 months or more. Most offenders are male (98.3 per cent), most convictions of NFS result from a plea of guilty ( 99 per cent) and once convicted there is a very high chance of imprisonment ( 76 per cent of offenders are imprisoned with an average sentence of 1.9 years) (Sentencing Advisory Council, 2019, p. 2).

\section{Method and approach}

In this study we interviewed 17 lawyers who had prosecuted or defended charges of NFS in Queensland, Australia over the preceding year. Interviews took place over zoom in December 2020 and each interview lasted approximately one hour. Author one undertook all the interviews. Prosecutors were recruited via the Office of the Director of Public Prosecutions (ODPP) in Queensland and defence lawyers were recruited through the criminal law section of the Queensland Law Society and through the Queensland Bar Association. Within the ODPP, recruitment involved potential participants being initially approached by the Directorate in the ODPP who provided information about the study. If they were interested in participating and expressing their private views the Directorate put their names and contact details forward to the researchers who subsequently contacted the prosecutors and arranged interview times. Recruitment of defence lawyers was carried through the Queensland Law Society criminal law section who made suggestions of defence lawyers (both barristers and solicitors) in Queensland for researchers to contact. While there is a lot of movement and cross-over between work as a prosecutor or defence lawyer in Queensland, at the time of interview six participants were working as prosecutors and ten were working in criminal law defence. Three of the defence lawyers worked for a community legal service, two were barristers and five worked in a private criminal law firm. All of the lawyers interviewed had experience both in preparing files, proofing witnesses, appearing in court in relation to bail applications, sentencing and trials involving charges of non-fatal strangulation.

The interview transcripts were thematically analysed (Braun and Clarke, 2006) manually by both of the authors in light of the evidential issues raised in the literature: the importance of visible injuries to successful prosecution of NFS, the role of expert evidence, the availability of third party witnesses and 
other corroborative evidence, the role and importance of the complainant's testimony and the willingness of complainants to testify. The study received ethical approval from the University of Queensland Human Ethics Committee (approval number 2020000558).

\section{Study Findings}

\section{The importance of injury}

The role of injuries in the prosecution of NFS was discussed by many of the participants. In terms of the kinds of injuries seen in NFS cases, most participants pointed to red marks on the neck, but other visible injuries were also sometimes noted as being present:

We often will see general redness to the neck or throat area, which defence will try and minimise the effect of because it's just general redness. We sometimes do get fingerprint impressions, bruising from the fingertips that the medical officer can talk about. And often, there are scratch marks and things like that that are also involved. (Lawyer 11- DPP)

Several participants noted that red marks may be present when the police arrive at the scene, but they are unable to be photographed in any useful evidentiary way, and disappear quite quickly (Reckenwald, King \& Pritchard, 2020, p. 168):

We usually have photos. But they don't usually show much. You'll get grainy photos that are taken by the police on the night they attend, and you could be looking at anything, really. They'll say that they observed maybe a red mark, or a faint mark, or something like that. But I certainly haven't had a matter where there's been serious bruising, or physical injury that's able to be observed in photographs clearly. (Lawyer 6- Def)

One participant described the difficulty of defending a charge of NFS in these circumstances: "how do you defend, that police officer's observations which you then can't say existed a short time later when they were photographed. It makes it very hard to understand how that proof is going to develop in court.' (Lawyer 7- Def) The fleeting nature of the redness on the neck also means that people who delay calling for help, which is not uncommon in cases involving domestic violence (Gruber, 2020, p. 194) or who live remotely and therefore the police response is slower or transport to hospital is delayed, are more likely to no longer have visible injuries resulting from the NFS: 'there won't be a transportation to a hospital if it's in a remote community. It might just be a complainant saying this happened or they might not come forward until sometime after where there's no opportunity for police or doctors to witness or see any physical injuries.' (Lawyer 11- DPP) This participant also observed, consistent with other research (Baker \& Sommers, 2008), that, 'the other issue... with injuries to the external parts of the body on an Indigenous victim is you often can't see the redness that you might see on a Caucasian person or those features that can be very obvious in Caucasian complainants.' (Lawyer 11- DPP)

Some participants said that the presence of visible injuries may be one of the considerations underpinning a decision to take a matter to trial. For example:

I do think, and I've often thought this, when thinking about whether to take something to trial, that the absence of evidence, I think would still be somewhat persuasive to a jury. I think a jury 
'Proving non-fatal strangulation in domestic violence cases'. Authors: Heather Douglas and Robin Fitzgerald. Accepted version: International Journal of Evidence \& Proof.

even though they'd probably be directed otherwise, the jury might intuitively think if he's done what she says he's done, you'd expect to see something. (Lawyer 3- Def)

However, most participants accepted that NFS often leaves no visible injuries, so the lack of visible injuries was possible to explain as not inconsistent with NFS:

... it's very easy for the prosecutor to counter that because of the weight of research evidence that says, well, it's not uncommon for this type of offence to not leave a mark. (Lawyer 2- Def)

Most of the time, you're seeing red marks on the neck. If you get that, fantastic. But the absence of red marks doesn't exclude that the offence occurred. It might make the case a little bit weaker, but it doesn't exclude it. (Lawyer 16- DPP)

In particular, some participants highlighted that the NFS offence requires hindering of the breath and therefore the lack of, or presence of, a visible injury neither supports nor refutes the occurrence of NFS:

... [presence of physical injury] it might demonstrate some level of assault, but it won't necessarily [show] a lack or restriction of breath that we need to prove for a choking. And equally, it's often associated with a volatile relationship where the accused is saying, I did touch her in some way, shape, or form, but it was entirely defensible. (Lawyer 13- DPP)

Summary. Participants focussed on the presence or absence of visible injuries. While participants said that the presence of visible injuries may help to persuade juries to convict NFS, all participants agreed that the absence of visible injuries was not fatal to the successful prosecution of a charge of NFS. In part, this is because the lack of visible injury is broadly accepted amongst lawyers to be common in NFS cases and their absence can be explained but also that the offence itself requires breath to be hindered and this is not proven by the presence of visible injury. Furthermore, participants highlighted the most common visible injury associated with NFS, redness of the neck, is often fleeting, not observable on people with darker skin and potentially ambiguous in relation to its cause.

\section{The role of medical expert evidence}

According to participants, the Court of Appeal's ( $R v$ HBZ [2020] QCA 73) determination that NFS requires the restriction of breath 'lessens the importance of medical evidence' (Lawyer 16- DPP). But even though it was common for medical evidence, which lawyers described primarily as constituting a 'medical statement' or a 'medical report', to be included in the brief of evidence, defence lawyers emphasised that medical evidence was usually ambivalent at best: 'there's rarely medical evidence that supports the allegation one way or another. Usually it's neutral...' (Lawyer 6- Def); 'I don't think it [medical evidence] adds much' (Lawyer 10- Def); 'it's not conclusive as to what's actually occurred...' (Lawyer 5- Def) and '...doctors always come and say, look, likely, but I can't say yes or no' (Lawyer 4- Def).

One participant argued that medical evidence in NFS cases played a similar role as it does in sexual assault cases:

... doctor statements saying, only one case obviously noting marks to the neck, bruising to the neck and in the others saying, "there isn't any. But that doesn't mean it hasn't occurred", which is again similar to sexual assault in that you get medical evidence which really it's neither here nor there. (Lawyer 3- Def) 
Despite the ambivalent role medical evidence plays in the successful prosecution or defence of an NFS charge, participants said it was common for medical evidence to be part of the brief of evidence. Similar to other types of offences, commonly, a statement from a doctor at the hospital where the complainant attended or from a general practitioner was part of the brief of evidence: 'if she's gone to the doctor or to the hospital immediately following the event, then there would be those medical statements.' (Lawyer 2- Def) One participant reported: 'I've seen the doctors statement saying "I assessed them shortly afterwards. [There was] pain around the neck" or whatever it might be, which is consistent with the reported version.' (Lawyer 8- Def)

Where the complainant attended a medical practitioner in the days following the event of NFS 'a doctor might effectively recite the complaint but say that they can't say whether or not that's actually occurred based on the medical assessment. ... But they'll always stop short of saying that's [NFS]... ' (Lawyer 6- Def) Others noted that hospital social workers or counsellors provided statements saying: 'this was what was reported [by the victim] to me.' (Lawyer 1- Def)

From the prosecution perspective, expert medical evidence can be important in educating juries that the absence of visible injury is not unusual in NFS cases and that a very small amount of pressure can restrict the breath. For example:

The forensic medical officer team have ... been prepared to come along and say, even in the absence of injuries, that doesn't mean this person wasn't choked in the way they've described because there's in fact literature to suggest that a large number of these matters wouldn't produce any real injuries because the ability to choke someone depending how you go about doing it can actually require very little pressure at all ... the [medical officers] will use that in comparison to a handshake, and I think it's about a fifth of the pressure required for a normal handshake is required to choke someone, so it's not unsurprising that you won't see bruising or other identifiable features. (Lawyer 13- DPP)

A prosecution participant highlighted that the jury didn't need a medical expert to identify the small amount of pressure needed to constrict breath, explaining: 'I've even...said to the jury, you can hold your own throat and you can feel the constriction, and take your own hand away. You don't need a bruise to feel your throat closing over.' (Lawyer 16- DPP)

Only one participant discussed internal injuries associated with NFS noting that medical evidence can address features common to NFS such as hoarseness of voice and difficulty swallowing: 'And it's often a combination of those features that make it stronger evidence, less ambiguous if we only had one of those features at play'. (Lawyer 11- DPP)

Interestingly, one participant pointed out that it will be the most serious cases of NFS that will be accompanied by relevant medical evidence and when that is available a more serious charge is likely to be pursued:

... the reality of it is that there's rarely going to be medical evidence. Sometimes there will be. In the really severe cases, there might well be and then you'd be looking at a [grievous bodily harm] with intent or attempted murder or something like that. (Lawyer 2- Def) 
Summary. Possibly juries are easier to convince about the intent to commit harm where, for example, serious bruising on the neck is present, and charges requiring a specific intent (such as grievous bodily harm or attempted murder) are associated with much higher penalties than NFS. ${ }^{5}$ While the presentation of some form of medical evidence was common in NFS cases, it usually did not assist in the prosecution or defence of NFS cases. Most doctors, if called, found medical evidence ambivalent at best. However, there was general agreement from prosecuting lawyers that a doctor's evidence that the absence of injury was not inconsistent with NFS was useful in challenging juries' expectations that such a serious offence would necessarily be accompanied by obvious injury.

\section{The availability of third-party witnesses and other corroboration}

Most participants observed that, similar to other forms of domestic violence (Epstein and Goodman, 2018; Hunter, 1996, p. 160), there are usually no witnesses to the incident of NFS: 'it's done in the privacy of the home where there's no other witnesses available' (Lawyer 11- DPP); 'I think I've only had one matter where the offence has happened in public, and there were other witnesses to the incident.' (Lawyer 6Def)

A lawyer who acts for many Aboriginal and Torres Strait Islander clients described different reasons for the lack of corroborating witnesses: 'Look, there's truth that this one is familial obligation. I won't dob on my mate, or sister, or cousin or whoever it might be ... There is the solidarity factor. "I just didn't see anything." "I was too drunk." "I don't know." "I don't remember." There is a lot that happens around all of these interpersonal conflicts.' (Lawyer 8- Def) This participant also speculated there might be 'over laziness' on the part of police in collecting evidence about 'black on black domestic violence', noting that police may not bother to get third party statements as they know there will be 'resistance'.

Others said that there were usually no witnesses who actually saw the NFS but pointed out there were often witnesses available who could provide testimony of other forms of 'corroborative' evidence or context evidence (Campbell, 2019). For example:

... there's a neighbour who hears the argument or there's her running out of the house or her immediately calling the police and saying, Barry just strangled me....Yes, there's a lot of other corroborative evidence that then makes the whole incident real because there obviously was a fight. The neighbours heard the fight. The neighbours heard you call her a C-U-N-T. The neighbours saw her run out of the house. (Lawyer 4- Def)

There's often not witnesses, but you know, the corroboration around it. If I can use that term fairly loosely. [There] is often screaming, yelling heard by neighbours, by others in different rooms. That gives some context to an argument or a fight. Or obviously, there's some background evidence that's there. (Lawyer 7- Def)

A general exception to the lack of eyewitnesses to NFS is children. Several participants pointed out that there were sometimes child witnesses of events. In Queensland, where this research took place, the admissibility of evidence is governed by the Evidence Act 1977 (Qld) and this legislation includes special provisions for dealing with children's evidence (Evidence Act 1977 (QId) section 9E). Pursuant to this

\footnotetext{
${ }^{5}$ See sections 317 QCC (Intended Grievous Bodily Harm- maximum life imprisonment) and 305 QCC (Attempted Murder- maximum life imprisonment)
} 
legislation children are presumed competent to give evidence unless there is an objection, and the court will make the final determination about this (Queensland Courts, 2021b, [12.1]). Participants suggested that the availability of child witnesses can be an important factor in NFS matters not going forward to trial with parents on both sides wanting to avoid traumatising their children:

I must say, a lot of the time, my clients are unwilling to force the children to become involved. And that often becomes a basis to try and resolve things. Because they don't want the children to have to give evidence. (Lawyer 6- Def)

... that is one of the big features that the complainants will show reluctance about once they find out that the child will need to give evidence and be cross-examined about what they saw dad do to mum or stepdad do to mum or whatever it might be. There is a real hesitation by complainants to put their children through the process. (Lawyer 11- DPP)

There may also be ethical questions for lawyers to grapple with in deciding to engage children as witnesses because of the potential for trauma, and while children may be competent to give 'an intelligible account of events' (Evidence Act 1977(QId), s9A) they may not understand the wider impacts of their evidence on their parents and their lives:

[on children] ...that's really a difficulty, because at the end of the day you're asking a child if they do give evidence, to give evidence against mum, or dad ... It's hard for them to reconcile, and so it does have those adverse consequences. They haven't made a free, and informed decision about what they want to do, and so that's why I say it's a mixed bag. Because they've got that emotional turmoil that they're not old enough to really deal with, or grapple with, and realise that it's for the greater good. (Lawyer 14- DPP)

Generally, lawyers expressed discomfort with children testifying in cases of one parent assaulting another: 'Look, it's awful stuff. Cross-examining kids and having little kids bloody come on, give evidence, hard stuff.' (Lawyer 4 - Def)

Summary. Similar to other forms of domestic violence, because of the private nature of NFS incidents, there are rarely third-party witnesses, with the exception of children. However, the use of child witnesses is described by lawyers as problematic - complainants are reluctant to support having their children testify and children themselves can experience harm from the process. One participant pointed to the reluctance of Aboriginal third-party witnesses to give statements to police in cases involving domestic violence offences where Aboriginal people are both victims and alleged offenders. This participant also pointed to a lack of police engagement with these types of investigations, attributing their lack of engagement to an expectation that Aboriginal people are likely to refuse to provide a statement. As Porter and Cunneen (2020: 409) show, the relationship between Aboriginal Australians and police was forged in 'colonial warfare, child removal, genocide and institutional racisim' creating a relationship of deep distrust. This distrust is most likely to explain the reluctance of Aboriginal people to provide statements and police expectation of this reluctance.

\section{The role and importance of the complainant's testimony}

Despite the single incident nature of NFS and the common presentation of visible injury - although such injuries are often ambiguous in relation to their cause - most participants said that successful 
prosecutions of NFS substantially rely on the complainant's testimony and perceptions about the complainant's credibility. This is also the case for many domestic violence related crimes (Temkin, 2000; cf Bishop \& Bettinson, 2018). This view was held by both prosecution and defence lawyers. For example prosecution lawyers stated: 'It's usually word on word' (Lawyer 15- DPP); 'so it comes down to that reliance on the complainant' (Lawyer 16- DPP); 'I think the strongest evidence we would ever have is the victim's evidence' (Lawyer 14- DPP).

Similarly, defence lawyers highlighted the importance of the complainant's evidence: 'it will be, like all DV, very often it's the evidence of the aggrieved against the evidence of our client' (Lawyer 8- Def). Defence lawyers pointed out that the credibility of the complainant was a key assessment they made before advising their clients on plea, for example:

In defending these matters, medical evidence becomes important to explain away some of those issues, and what other possibilities are alive. But in terms of, when am I going to advise a client to plead guilty to that offence? It's when there is that evidence but combined with a persuasive account from a complainant. (Lawyer 10- Def)

Where defence lawyers could point to trials they had won, they routinely pointed to the lack of credibility of the complainant as a significant aspect of the case:

The trials that we won was a credit issue for the complainant. It's not necessarily that it was a technical of you didn't actually strangle the person. It was more of she's telling fibs. Here is the credit that goes behind it. (Lawyer 4- Def)

We won the trial because she wound up being unreliable, and what we found via by our subpoenaed evidence... whenever she had a relationship that was going pear-shaped, she would have these just terrible outbursts, and it was consistent. (Lawyer 5- Def)

Defence lawyers have a vested interest in gaining the best result for their client who is charged with NFS, which generally is a withdrawal or an acquittal of a serious charge such as NFS. Given the focus on the complainant's credibility, it is not surprising that defence lawyers often construct complainants as lacking credibility. For example, some defence lawyers spoke about the role of criminal prosecutions of NFS in informing family court decisions about child contact and how this might lead to false complaints of NFS and also the use of allegations of NFS to encourage a timely and serious police response to domestic violence:

That particular one, honestly, that did feel like that allegation had been used in a family law dispute and it worked very effectively in that case. And I say that with caution because I know that that is a hot topic, and I know that it's something which is thrown around. But there are some cases where you think this was used in an unconscionable way. (Lawyer 3- Def)

I think complainants now know that the surest way of getting the aggrieved taken away is to say that they got strangled. But, at the same time, I think there's probably been lots of times that they were, that they didn't complain that they had been. (Lawyer 1- Def)

Summary. The complainant's evidence and her credibility remain pivotal in NFS cases, again this is similar to other forms of domestic violence. Despite the expectation of physical evidence associated 
with NFS (Strack et 2011), it can often be discounted based on its ambiguity, as explained earlier. The lawyers interviewed present a familiar story. Ultimately, they are focussed on the credibility of the complainant's testimony (Simon-Kerr, 2021, p. 3) with defence lawyers, in particular, identifying reasons why a complainant may manufacture an NFS complaint.

\section{The willingness of complainants to testify}

Consistent with previous research (Robinson \& Cook, 2006) all participants said it was not uncommon for complainants to retract statements and to try to have charges arising out of domestic violence withdrawn. Participants highlighted that complainants were more likely to seek to retract statements alleging, and to withdraw charges of, NFS than other domestic violence related charges: 'It seems to me, and just my anecdotal experience, that in terms of people wanting to withdraw complaints or disengaging with the prosecution, choking just seems to be the offence that attracts it the most.' (Lawyer 16- DPP)

Reasons for retraction. Both prosecution and defence lawyers referred to a familiar range of overlapping reasons for retraction and withdrawal efforts (Gruber, 2020, p. 194), including fear of what the alleged perpetrator will do if the charge is finalised, emotional connections, and material reasons such as loss of financial support and assistance with the care of children:

....and often, it is that the defendant is the main breadwinner of the family. We often have women that will say... And we had one only a couple of weeks ago saying that they didn't want to go through with it because they couldn't deal with knowing that they were responsible for their children's father being sent to jail, e.g. A lot of the time, it comes from their reluctances from the stability that is provided by that particular person or the relationship with children, like we've said... time also, it's just pure fear of the person [inaudible] going through with it and what might happen as a result of them going through with it. But that reluctance shows through as well... (Lawyer 11- DPP)

As one participant highlighted, the complainant's assessment of whether or not to proceed with assisting the prosecution may be a rational calculation of what's best for her and her children:

... if the defendant is still in custody the victim is then saying, well the source of income for the house, in custody. I now have two, or three children whom I have to look after by myself...They go through this check and balance. Am I better off without them, in that they're not assaulting me? Or am I better off to cop the flogging, pardon my vernacular. But am I better [off] to be the victim, but at least when I'm not the victim they're here to provide some sort of support in some way? (Lawyer 14- DPP)

If the accused is on an insecure visa, a prosecution of NFS can lead to deportation pursuant to the 'character ' test (Migration Act 1958 (Cth), s501), and in circumstances where the complainant's visa is dependent on the accused's visa, potentially both the offender and the complainant can be deported (Segrave, 2017). This can provide another reason for the complainant to retract her statement. One participant commented: 'I've had one where the person was not an Australian national. So, they were going to be deported and they had children here. The partner then believed that it is best to discontinue...' (Lawyer 12- DPP) 
Complainants may also be concerned about the impact on their social relationships if they assist with a prosecution. A prosecution may leave the complainant isolated, not just because she loses her relationship with the children's father who is in custody, but his family might stop helping out and the broader community may blame her for the prosecution and isolate her:

With domestic violence, there is a fair bit of, I don't want to do it because I still love him, and the financial pressures of not being in a relationship, and the social pressures, the community pressures. (Lawyer 15- DPP)

Relationships. Seeing the consequences. Feeling probably pressure from family members and others who then blame the complainant. Particularly in smaller communities. And there's a lot that goes into family relationships. I know I'm not telling you anything you wouldn't know but the idea that someone that is suddenly in custody can mean so much is just changed in an instant ... And in particularly more vulnerable sections of the society, those family networks, those friendship networks are sometimes all what people have to get by. To have kids looked after here and there. All of that is suddenly thrown out. And it's just that sense can motivate a complainant to say, this is really beyond what I thought was going to happen. (Lawyer 7- Def)

Some lawyers highlighted that the level of the enmeshment of the accused and complainants' lives influenced whether a complainant was likely to try to discontinue with proceedings, regardless of her level of her vulnerability. Those complainants who were more enmeshed with the accused were more likely to try to stop the prosecution than those who were in a relatively new relationship with the accused:

There are some who ... are very vulnerable witnesses who are in long-term relationships with children, where you can see there are other things on their mindsets ...Their access to children, their financial wellbeing, things like that. As opposed to someone who might be a drug offender who's only been with the perpetrator who's also a drug offender for a period of 12 months. They have no joint assets, no children, nothing else to worry about. (Lawyer 13- DPP)

The delay in closure of NFS matters also contributed to retraction and withdrawal. Because an NFS charge must be dealt with in the higher (District) courts, it can commonly take up to twelve months for the charge to be finalised. By the time the matter finally gets to court, the parties may have separated and stopped having contact with each other and complainants 'just don't want to go through that anymore' (Lawyer 6- Def), 'there's often a softening of the position of the complainant for various reasons' (Lawyer 12- DPP). Further, some complainants make a complaint not being aware of the (almost) inevitable jail penalty associated with the successful prosecution of the charge: 'we get a lot of victims or would-be victims who tell the police there's been a choking, not realising that that means that their partner's not coming home, and then retract the statement pretty quickly.' (Lawyer 16- DPP)

Complainants' efforts to retract and withdraw and associated risks. Prosecution participants highlighted the energy and resources expended by some complainants to withdraw their complaints, sometimes engaging family members to, in effect, lobby the prosecution to withdraw charges or employing lawyers to represent complainants in their efforts to have charges withdrawn: '...the complainant has refused to talk to us and taken on board lawyers in an attempt to block us. Then said we're only speaking through that person.' (Lawyer 12- DPP)

Most prosecution participants provided examples of complainants seeking to retract their statements and provide a new statement that did not implicate the offender in NFS. This created many issues for the 
prosecution but also had potential negative consequences for the complainant into the future. Where the prosecution receives two versions of events in statements made by the complainant they are obliged to disclose that to the defence (Criminal Code 1899(Qld) s590AB) and once there are two versions of events on file this can be used to challenge the complainant's credibility, not just in the prosecution of the NFS charge but in future allegations and other forums including the family law and protection orders courts:

... if someone says that they lied and that they made up allegations against their partner, then they need to know that that is something that we may have to disclose going forwards... So, the more extreme ones will try and say they've lied, and they might be teed up to that by an experienced defendant. And when that is said to us, that puts us, as a prosecutor, in a very difficult position because, in essence, it means that we then can't rely on that witness as a witness of credit. (Lawyer 15- DPP)

we have the vexed issue that if we push forward and they then go on the stand and swear to the fact that they've lied, who's going to believe them next time they make a complaint? And we're in The Boy Who Cried Wolf territory. (Lawyer 16- DPP)

Similar issues arise where the complainant is pressured into giving evidence at trial and offers a different version of events at that stage: 'We've had complainants who have committed offences of perjury by lying on oaths as to saying that this didn't happen when it clearly did. All those sorts of things.' (Lawyer 12DPP)

In some cases, complainants develop an alternative narrative, that might implicate others in the NFS perpetration, including children of the relationship. A prosecuting lawyer referred to a case where:

... the victim is saying that the bruises on her neck caused by the strangulation weren't in fact caused by the defendant, but they were caused by her children. So that's going to work in reverse. Either we're going to have to force the children to give evidence to deny or confirm that. Or we're just going to have to... Let it go. (Lawyer 12- DPP)

Lawyers' responses to withdrawal and retraction. When faced with a complainant who seeks to retract her statement or to have the charge withdrawn, prosecutor participants highlighted the balancing act they need to manage: 'You don't want to be in a position where your complainant is reluctant or you're essentially causing them trauma by you continuing with the prosecution. But, on the other hand, you don't want to give sanction to an offender [who] just says, can you drop it, and they do' (Lawyer 15DPP). One prosecutor explained that a 'gentle' approach was necessary to ensure that the complainant would be willing to engage at some future time if that was necessary:

So, you've got to be real careful about getting your complainant offside, thinking they can't come forward because they've lied to you. So, my view is you've got to take a really gentle approach. Even though it's quite flagrant and even though it's a complete waste of time and resources, I still think we need to take a very gentle approach because if he does something bad again, they need to come forward. They need to tell us. (Lawyer 16- DPP)

Prosecutor participants shared several strategies they used to discourage the retraction of the NFS allegation. For example, explaining the potential effects, as noted earlier, of having two inconsistent 
statements on file, and trying to encourage her to not to be inconsistent: 'If the victim is clearly lying ... [I] point out inconsistencies or issues in the case and get them to comment on it' (Lawyer 11- DPP). In matters where prosecutor participants believed the complainant had been put under pressure by the accused, they may encourage police to investigate, and potentially charge, pervert the course of justice (Criminal Code 1899 (Qld), s140) offences, or in other cases they may seek to lead evidence about the accused's pressure on the complainant to show consciousness of guilt (Queensland Courts, 2021b, [50.1]). Recorded prison calls made between the accused and complainant can underpin such charges or be used as evidence of consciousness of guilt:

Sometimes we will indict an attempt to pervert and include that on the indictment if it's really a serious interference. Other times, we will leave it up to the police as to whether they charge them with attempt to pervert or whatever they might decide ... [We] will often just ... lead that type of evidence as consciousness of guilt, as opposed to it being a particular charge on an indictment. But there are other cases where we will have it on the indictment and proceed with it. (Lawyer 11- DPP)

Participants from a defence background also reflected on the complexity of these issues:

[We] usually find that the client has somehow been in contact with [the complainant]. And then, that's been recorded, and then they've got a further charge coming. And she's been complicit in that. She's written to the respondent under a different name. ...It's all coded, yes. ... "And call me on this number, and this is the name of the person that will answer it," and it's her. And then, our guy gets charged. ...It is a very complex web. DV is very messy. It's always very messy. (Lawyer 1Def)

Some defence participants did not view the prosecution's approach to reluctant witnesses as 'gentle'. For example, one defence participant described complainants as being 'forced into prosecuting it by the system' and 'the prosecution will push them to the final hearing, or at least up to a trial date'. (Lawyer 10Def). Another explained: 'It's hard for complainants in DV generally ... they often try and withdraw the charges. And the police won't let them, and sometimes that's right, and sometimes that's wrong. (Lawyer 1- Def). Prosecution guidelines outline that discontinuance of charges will be favoured in circumstances where the offence is relatively minor but that 'the more serious the injury, the greater the public interest in proceeding' (Department of Justice and Attorney General, 2016, [22]). For prosecution participants in the sample, the complainant's reluctance was an important aspect of the case but the determination about whether to continue the charge depended on an assessment of the whole of the evidence. Therefore, a complainant's reluctance did not necessarily result in the charge being withdrawn, as one prosecutor participant explained:

Now if the victim comes back and says, I don't want to proceed with it, it didn't happen, but we've got red marks, we've got all the [unclear] of a choking, well maybe then that's a question of, are our prospects of success increased because we've got objective evidence? Marks on the throat don't necessarily prove anything in and of themselves, so then that's a question of, how significant is that evidence? (Lawyer 14- DPP)

Summary. Participants highlighted that NFS complainants were more likely to try to retract or change their statement so that their intimate partner was not implicated compared to other types of domestic violence related offences. This may be explained in several ways. First, the higher numbers of 
attempts to retract and withdraw may be related to the almost inevitable jail penalty that offenders are likely to face, if found guilty. Also playing into this phenomenon is the delay of the final hearing in NFS matters. As NFS must be heard in the higher courts in Queensland there is often a twelve-month delay between the event of NFS and the final hearing. This provides opportunities for survivors to consider whether their partner's incarceration is the best result (for the survivor and /or the children), considering their converging interests- childcare, visa, housing, social, financial and other needs (Gruber, 2020, p. 194; Ford, 2003). It also provides opportunities for accused people to exert influence and coercion on the complainant. While prosecuting lawyers use strategies to encourage and sometimes pressure the complainant to maintain their original narrative of events and thus support the prosecution, this may have unintended consequences in forcing complainants to use alternative strategies to get what they want or perceive they need to remain safe. For example, survivors might use scarce resources to engage their own legal support and tell ever more complex narratives that may have negative implications for their future safety and that of their children. Prosecution lawyers must determine what is best for the on-going safety and well-being of the complainant. Where her testimony is necessary for the prosecution to go forward, how far do they go? In making this decision it is always important that prosecution lawyers understand what underpins her efforts to withdraw from prosecution. Many of the prosecution lawyers we interviewed showed an appreciation of the complex factors at play, including the alleged perpetrator's continuing pressure, threats, intimidation and violence and her ongoing experience of fear and danger along with more material concerns. The prosecution decision is often a far from simple question to answer.

\section{Discussion and conclusion}

The successful prosecution of NFS appears to face challenges that are common to domestic violence offences more broadly. Some have argued that improved medical evidence can make prosecution of NFS more effective (Strack \& Gwinn, 2011). However, given the gravamen of the NFS offence in Queensland is that the NFS must hinder or restrict the breathing of the victim ( $R \vee H B Z$ [2020] QCA 73 [56]-[57]), in most cases more and better medical evidence, or evidence of internal injuries, is unlikely to assist the prosecution of NFS in the absence of the complainant's testimony. Training more experts who are willing and able to explain to juries that a complainant's breath may have been stopped by the accused's actions and yet not caused any visible injury may assist with prosecution (Strack \& Gwinn, 2011). Notably though, as one prosecutor suggested, inviting jury members to "hold your own throat and you can feel the constriction...you don't need a bruise to feel your throat closing over' (Lawyer 16- DPP) might be just as persuasive as medical evidence, and much less costly.

It seems that, like other domestic violence charges, central to the challenge of successful prosecution is the complainant's engagement with the prosecution process and her credibility. The comments of the participants in our study point to some practical ways to improve the retention of the complainant in the process including recognising the effects of trauma on the victim (Bishop, 2019; Ellison and Munro, 2017) responding to her safety and material concerns but also explaining the potential credibility problems the complainant may face in future if there are multiple versions of events on file.

One issue that may contribute to complainants' disengagement with the criminal justice system is delay (Ellison and Munro, 2017, p. 184). If matters were finalised more quickly there may be less opportunity for complainants to be influenced by the accused. However, speeding up the process may also reduce the time and distance available to complainants to assess whether criminal prosecution (and the incarceration of their abuser) is what they want and in their best interests or the best interests of their children. In short 
while some women are pressured by partners, who they fear, to retract statements, many women have well-considered reasons for doing so. The 'gentle' approach favoured by one prosecution lawyer (Lawyer 16- DPP) that focusses on the safety of the complainant and the importance of her willingness to engage at a future time with the criminal justice process seems to strike the right balance between allowing a complainant full autonomy versus pushing the complainant to engage on the current matter.

Given the dangers associated with NFS, incarceration may be appropriate for some NFS offenders. However, more penalty options in the context of domestic violence offending may improve survivors' engagement with the criminal justice process (Holder \& Mayo, 2003; Holder, 2019). Most research with survivors of domestic violence has found that survivors want their partner to stop being violent and minimise the impact of the abuse on their lives (Sharp-Jeffs, Kelly \& Klein, 2018; Lewis, Dobash, Dobash \& Cavanagh, 2000; Douglas, 2021). Thus, applying penalties that support and encourage behaviour change while still focussing on the survivor's safety, may keep some complainants engaged. The blunt and inevitable incarceration response may be contributing to the high number of complainants seeking to withdraw their support for prosecution. In the Queensland context reducing delay and improving penalty options for NFS would require both a legislative and policy change. ${ }^{6}$

Less clear is how to improve the perception of the complainant's credibility in NFS prosecutions. Complainants presenting inconsistent stories and multiple versions, delayed disclosures and a lack of coherency all play into credibility challenges (Smith \& Skinner, 2017). A supportive prosecutor, along with other survivor support, may help to keep the complainant engaged and encourage her to maintain a consistent narrative of events. However, many of the credibility issues are associated with trauma and this is often inadequately recognised in the criminal justice system (Bishop, 2019, p. 223). Bishop (2019, p. 235) has made a number of suggestions that might reduce the trauma associated with giving evidence including placing limitations on cross-examination and introducing ground rules hearings to determine the manner and content of questioning during cross-examination. Ellison and Munro $(2017$, p. 189) have also suggested several strategies that may assist jurors to assess testimony through a trauma informed lens, for example by providing information to juries about the effects of trauma on testimony. After our interviews were completed, Queensland introduced a pilot of an intermediary scheme (QIS). The pilot QIS is aimed to support child witnesses in sexual assault cases but if successful, consideration could be given to expanding such a program to victims of domestic violence offences, such as NFS. Intermediary schemes aim to 'allow vulnerable witnesses an opportunity to be heard, and to give their best evidence in order to assist in the administration of justice' (Queensland Courts, 2021c). In the QIS, intermediaries are engaged to assess vulnerable witnesses and advise on their communication needs and also provide practical strategies for police, lawyers and judges on how best to communicate with the vulnerable witness to obtain the best evidence (Queensland Courts, 2021c). Under the pilot QIS, intermediaries will be able to provide a report to the court that will inform a directions hearing (similar to a ground rules hearing) in an effort to ensure the vulnerable witness understands the proceedings and is supported to give her best evidence (Queensland Courts, 2021c).

Our focus in this paper has been on the criminal legal system but the usefulness of this system to survivors of domestic violence has long been contested (Smart, 1989) and is increasingly so (Gruber,

\footnotetext{
${ }^{6}$ For example, although NFS is an indictable offence is might be possible, with statutory reform to hear it in the lower courts in certain circumstances, eg see QCC Chapter 58A, this would reduce the time to finalisation by about half in most cases.
} 
2020; Goodmark, 2018). Other responses including civil justice mechanisms but also responses that decentre the law (Smart, 1989, p. 161) including a focus on health, poverty and human rights may offer better pathways for survivors of violence.

\section{References}

Australian Institute of Criminology (2019) Homicide in Australia 2014-2015. Sydney: Australian Institute of Criminology.

Australian Institute of Criminology (2020a) Homicide in Australia 2017-18 Sydney: Australian Institute of Criminology.

Australian Institute of Criminology (2020b) Homicide in Australia 2016-2017. Sydney: Australian Institute of Criminology.

Australian Law Reform Commission (2010) Family Violence- A National Legal Response. Sydney: Australian Law Reform Commission.

Baker R B and Sommers M S (2008). Physical injury from intimate partner violence: Measurement strategies and challenges. Journal of Obstetric, Gynecologic, \& Neonatal Nursing, 37:228-233. doi: 10.1111/j.1552-6909.2007.00226.x

Bichard H, Byrne C, Saville C and Coetzer R (2021) The neuropsychological outcomes of non-fatal strangulation in domestic and sexual violence: A systematic review. Neuropsychological Rehabilitation online first. do: 10.1080/09602011.2020.1868537

Bishop C (2019) Safe and Effective Courtroom Participation for Domestic Violence ComplainantWitnesses. In Child J and Duff R A (eds) Criminal Law Reform Now: Proposals and Critique. London: Hart Publishing, 223-242.

Bishop C and Bettinson V (2018) Evidencing domestic violence, including behavior that falls under the new offence of 'controlling or coercive behavior'. The International Journal of Evidence \& Proof 22(1): 3-29.

Bricknell S (2020) Homicide in Australia 2017-2018: Australian Institute of Criminology Statistical Report 23. Sydney: Australian Institute of Criminology.

Burton M, Evans, R and Sanders A (2007) Vulnerable and intimidated witnesses and the adversarial process in England and Wales. The International Journal of Evidence \& Proof 11(1); 1-23.

Campbell R (2019) Domestic relationship evidence in Queensland: An analysis of a misunderstood provision. University of New South Wales Law journal 42(2): 430-461.

Coker D (2001). Crime control and feminist law reform in domestic violence law: A critical review Buffalo. Criminal Law Review 4: 801-860.

Crimes Act 1900 (ACT)

Crimes Act 1900 (NSW)

Crimes Act 1961 (New Zealand)

Criminal Code 1899 (QId)

Criminal Code Act 1983 (NT)

Criminal Code 1985 (Canada)

Criminal Code Compilation Act 1913 (Canada)

Criminal Law Consolidation Act 1935 (SA)

Criminal Law (Domestic Violence) Amendment Bill (No. 2) 2015

Dennis I (2010) The right to confront witnesses: meanings, myths and human rights. Criminal Law Review 4: 255-274. 
Department of Justice and Attorney General, (2016) Director's Guidelines (Brisbane, Queensland Government), available at: https://www.justice.qld.gov.au/_data/assets/pdf_file/0015/16701/directors-guidelines.pdf Domestic Abuse Act 2021 (England and Wales)

Douglas H and Fitzgerald R (2014) Strangulation, Domestic Violence and the Legal Response. Sydney Law Review 36: 231-254. http://classic.austlii.edu.au/au/journals/SydLawRw/2014/11.html

Douglas H and Fitzgerald R (2020) Women's Stories of Non-Fatal Strangulation: Informing the Criminal Justice Response. Criminology \& Criminal Justice. doi: 10.1177/1748895820949607

Douglas H (2021) Women, Intimate Partner Violence and the Law. New York: OUP.

Dowling C, Morgan A, Boyd C and Voce I (2018) Policing Domestic Violence: A Review of the Evidence. Sydney: Australian Institute of Criminology. https://www.aic.gov.au/publications/rr/rr13

Edwards S (2012) The duplicity of protection - prosecuting frightened victims: An act of gender-based violence. Journal of Criminal Law 76: 29-52.

Edwards S (2015) The strangulation of female partners. Criminal Law Review 12: 949-966.

Edwards S and Douglas H (2021) The criminalisation of a dangerous form of coercive control: Non-fatal strangulation in England and Wales and Australia. Journal of International Criminal Law 8(1): 87120.

Ellison L (2002) Prosecuting domestic violence without victim participation. Modern Law Review 65(6): 834-858.

Ellison L (2005) Closing the credibility gap: The prosecutorial use of expert witness testimony in sexual assault cases. The International Journal of Evidence \& Proof 9(4): 239-268. doi: 10.1350/ijep.2005.9.4.239

Ellison L and Munro V (2017) Taking trauma seriously: critical reflections on the criminal justice process. The International Journal of Evidence \& Proof 21(3): 183-208. doi: 10.1177/1365712716655168

Epstein D and Goodman L (2018) Discounting Credibility: Doubting the Testimony and Dismissing the Experiences of Domestic Violence Survivors and Other Women. University of Pennsy/vania Law Review 167: 399-461. https://papers.ssrn.com/sol3/papers.cfm?abstract_id=3133066

Evidence Act 1977 (Qld)

Faugno D, Waszak D, Strack G, Brooks M and Gwinn C (2013) Strangulation Forensic Examination: Best Practice for Health Care Providers" Advanced Emergency Nursing Journal 35(4): 314-327. doi: 10.1097/TME.0b013e3182aa05d3.

Foley A (2015) Strangulation: Know the Symptoms, Save a Life. Journal of Emergency Nursing 14(1): 8990. doi: 10.1016/j.jen.2014.10.013

Ford D (2003) Coercing victim participation in domestic violence prosecutions. Journal of Interpersonal Violence 18(6): 669-684. doi: 10.1177/0886260503253872

Funk M and Schuppel J (2003) Strangulation Injuries Wisconsin Medical Journal 10241.

Glass N, Laughon K, Campbell J, Wolf Chair A, Block C, Hanson G, Sharps P and Taliaferro E (2008) NonFatal Strangulation Is an Important Risk Factor for Homicide of Women. Journal of Emergency Medicine 35(3): 329-335. doi: 10.1016/j.jemermed.2007.02.065

Gombru A, Brignell G and Donnelly H (2016) Sentencing for domestic violence (Sentencing Trends and Issues 45). Sydney, NSW, Australia: Judicial Commission of NSW. Available at: https://www.judcom.nsw.gov.au/wp-content/uploads/2016/07/sentencing_trends_45.pdf

Goodmark L (2018) Decriminalizing domestic violence: A Balanced Policy Approach to Intimate Partner Violence. Oakland: University of California Press.

Gruber A (2020) The Feminist War on Crime: The Unexpected Role of Women's Liberation in Mass Incarceration. Oakland: University of California Press. 
Holder R and Mayo N (2003) What Do Women Want? Prosecuting Family Violence in the ACT. Current Issues in Criminal Justice 15(1): 5-25. http://www.austlii.edu.au/au/journals/CICrimJust/2003/9.pdf

Holder R (2019) Just Interests: Victims, Citizens and the Potential for Justice. Cheltenham: Edward Elgar Publishing.

Howe A (2012) The Problem of Privatized Injuries: Feminist Strategies for Litigation. In Fineman $M$ and Sweet Thomadsen N (eds) At the Boundaries of Law (RLE Feminist Theory): Feminism and Legal Theory Taylor \& Francis.

Hunter R (1996) Gender in evidence: Masculine norms vs feminist reforms. Harvard Women's Law Journal 19: 127-159

Legal Affairs and Community Safety Committee (2016) Criminal Law (Domestic Violence) Amendment Bill (No.2) 2015: Report No. 23, 55th Parliament. Brisbane: Queensland Government.

Lewis R, Dobash RP, Dobash RE and Cavanagh K (2000) Protection, prevention, rehabilitation or justice? Women's use of the law to challenge domestic violence. International Review of Victimology 7(1): 179-205. doi: 10.1177/026975800000700310

Marks J, Markwell A, Randell T and Hughes J (2020) Domestic and Family Violence, Non-Lethal Strangulation and Social Work Intervention in the Emergency Department. Emergency Medicine Australasia 32: 676-678. doi: 10.1111/1742-6723.13519

Matusz E, Schaffer J, Bachmaier B, Kirschner J, Musey P, Roumpf S, Strachan C and Hunter B (2020) Evaluation of nonfatal strangulation in alert adults. Annals of Emergency Medicine 75(3): 329-338.

Migration Act 1958 (Cth)

Mills L (1998). Mandatory arrest and prosecution policies for domestic violence. Criminal Justice and Behaviour 25: 306-318. doi: 10.1177/0093854898025003002

Monahan K, Purushotham A and Biegon A (2019) Neurological implications of nonfatal strangulation and intimate partner violence. Future Neurology 14(3): online. doi: 10.2217/fnl-2018-0031

Mulvihill v R [2016] NSWCCA 259.

Patch M, Anderson J and Campbell J (2018) Injuries of women surviving intimate partner strangulation and subsequent emergency health care seeking: An integrative evidence review. Journal of Emergency Nursing 44(4): 384-394. doi: 10.1016/j.jen.2017.12.001

Porter A and Cunneeen C (2020) Policing Settler Colonial Societies. In Birch P, Kennedy M and Kruger E (eds) Australian Policing: Critical Issues in $21^{\text {st }}$ Century Police Practice. London: Routledge 397412.

Pritchard A, Reckdenwald A and Nordham C (2017). Non-fatal strangulation as part of domestic violence: A review of research. Trauma, Violence and Abuse 18(4): 407-424. doi: $10.1177 / 1524838015622439$

Queensland Courts (2021a) Domestic and family violence statistics, available at: https://www.courts.qld.gov.au/court-users/researchers-and-public/stats

Queensland Courts (2021b) Supreme and District Courts Bench Book, available at: https://www.courts.qld.gov.au/_data/assets/pdf_file/0016/86011/sd-bb-12-competency-ofwitnesses-including-children.pdf

Queensland Courts (2021c) Queensland Intermediary Scheme Pilot Program, available at: https://www.courts.qld.gov.au/services/queensland-intermediary-scheme/qis-pilot-program

Queensland Sentencing Advisory Council (2019) Sentencing Spotlight on choking, suffocation or strangulation in a domestic setting. Brisbane: Queensland Sentencing Advisory Council.

$R v H B Z[2020]$ QCA 73

$H B Z \vee R$ [2020] HCATrans 187

$R v$ Fraser [2020] SADC 127 
Reckenwald A, King D and Pritchard(2020) A Prosecutorial Response to Nonfatal Strangulation in Domestic Violence Cases" Violence and Victims 35(2): 160 -175. http://dx.doi.org/10.1891/VV-D-18-00105

Robinson A (2014) Pie in the sky? The use of criminal justice policies and practices for intimate partner violence. In: Johnson H, Fisher B and Jaquier V (eds) Critical Issues on Violence Against Women: International Perspectives and Promising Strategies. London: Routledge 66-76.

Robinson A and Cook D (2006) 'Understanding victim retraction in cases of domestic violence: Specialist courts, government policy, and victim centred justice.' Contemporary Justice Review 9 (2): 189213.

Segrave M (2017) Temporary Migration and Family Violence: An analysis of victimisation, vulnerability and support. Melbourne: Monash University. Available at:https://research.monash.edu/en/activities/report-launch-temporary-migration-and-familyviolence

Sharp-Jeffs, N, Kelly L and Klein R (2018) Long Journeys toward Freedom: The Relationship Between Coercive Control and Space for Action - Measurement and Emerging Evidence. Violence Against Women 24(2): 163-185.

Simon-Kerr J (2021) Relevance through a feminist lens. In Dahlman C, Stein A and Tuzet G (eds) Philosophical Foundations of Evidence Law, Oxford University Press: (Forthcoming). Available at https://ssrn.com/abstract=3762108 or http://dx.doi.org/10.2139/ssrn.3762108

Smith $O$ and Skinner $\mathrm{T}$ (2017) How rape myths are used and challenged in rape and sexual assault trials. Social \& Legal Studies 26(4): 441 - 466 https://doi.org/10.1177/0964663916680130

Sorenson S, Joshi M and Sivitz E A (2014) Systematic Review of the Epidemiology of Nonfatal Strangulation, a Human Rights and Health Concern. American Journal of Public Health 104: e54e61.

Special Taskforce on Domestic Violence in Queensland, (2015) Not Now Not Ever: Putting an End to Domestic and family Violence in Queensland, Queensland Government

Strack G, McClane G and Hawley D (2001) A Review of 300 Attempted Strangulation Cases, Part II: Clinical Evaluation of the Surviving Victim. Journal Emergency Medicine 21(3): $311-315$. doi: 10.1016/s0736-4679(01)00400-0.

Strack, G and Gwinn C (2011) On the edge of homicide: Strangulation as a prelude. Criminal Justice 26(3): 1-5.

Temkin J (2000) Prosecuting and Defending Rape: Perspectives from the Bar. Journal of Law and Society (27) 2: 219-248.

Thomas K, Joshi M and Sorenson S (2014) 'Do You Know What It Feels Like to Drown?': Strangulation As Coercive Control in Intimate Relationships. Psychology of Women Quarterly 38(1): 124-137 doi: 10.1177/0361684313488354\%20.

Training Institute on Strangulation and California District Attorneys Association (2013) The investigation and prosecution of strangulation cases (Training Institute on Strangulation and California District Attorneys Association).

Turkel A (2007) Understanding, Investigating, and Prosecuting Strangulation Cases. The Prosecutor 41(6): 20-23, available at: https://www.ojp.gov/ncjrs/virtual-library/abstracts/understandinginvestigating-and-prosecuting-strangulation-cases

Wilbur L, Higley M, Hatfield J, Surprenant Z, Taliaferro E, Smith D and Paolo A (2001). Survey results of women who have been strangled while in an abusive relationship. The Journal of Emergency Medicine, 21(3): 297-302. http://dx.doi.org/10.1016/S0736-4679(01)00398-5

Youngs J (2015) 'Domestic Violence and the Criminal Law: Reconceptualising Reform' Journal of Criminal Law 79: 55-70 doi: 10.1177/0022018314566746 
'Proving non-fatal strangulation in domestic violence cases'. Authors: Heather Douglas and Robin Fitzgerald. Accepted version: International Journal of Evidence \& Proof.

Zilkens R, Phillips M, Kelly M, Mukhtar S, Semmens J and Smith D (2016) Non-fatal strangulation in sexual assault: A study of clinical and assault characteristics highlighting the role of intimate partner violence. Journal of Forensic and Legal Medicine 43: 1-7. doi:

10.1016/j.jflm.2016.06.005

\section{Acknowledgments:}

Research supported by an Australian Research Council Discovery Project: DP200101020.

Ethics approval: University of Queensland Human Ethics 2020000558.

Thanks to the Office of the Director of Public Prosecutions (Qld) for their support and to the lawyers who were willing to be interviewed for this research. The authors thank the anonymous reviewers and Dr. Jamie Walvisch for comments on earlier versions of this article. 


\section{University Library}

\section{- M M N E R VA A gateway to Melbourne's research publications}

Minerva Access is the Institutional Repository of The University of Melbourne

Author/s:

Douglas, H;Fitzgerald, R

Title:

Proving non-fatal strangulation in family violence cases: A case study on the criminalisation of family violence

Date:

2021-10-01

Citation:

Douglas, H. \& Fitzgerald, R. (2021). Proving non-fatal strangulation in family violence cases: A case study on the criminalisation of family violence. INTERNATIONAL JOURNAL OF EVIDENCE \& PROOF, 25 (4), pp.350-370. https://doi.org/10.1177/13657127211036175.

Persistent Link:

http://hdl.handle.net/11343/282517 